\title{
Context dependency of biotic interactions and its relation to plant rarity
}

\author{
Anne Kempel ${ }^{1}$ (D) | Hugo Vincent ${ }^{1} \mid$ Daniel Prati $^{1} \mid$ Markus Fischer $^{1,2}$
}

\author{
${ }^{1}$ Institute of Plant Sciences, University of \\ Bern, Bern, Switzerland \\ ${ }^{2}$ Botanical Garden, University of Bern, Bern, \\ Switzerland

\section{Correspondence} \\ Anne Kempel, Institute of Plant Sciences, \\ University of Bern, Altenbergrain 21, 3013 \\ Bern, Switzerland. \\ Email: kempel@ips.unibe.ch \\ Funding information \\ Bundesamt für Umwelt \\ Editor: Amanda Taylor
}

\begin{abstract}
Aim: Biotic interactions can determine rarity and commonness of species, however, evidence that rare and common species respond differently to biotic stress is scarce. This is because biotic interactions are notoriously context dependent and traits leading to success in one habitat might be costly or unimportant in another. We aim to identify plant characteristics that are related to biotic interactions and may drive patterns of rarity and commonness, taking environmental context into account.

Location: Switzerland.

Methods: In a multispecies experiment, we compared the response to biotic interactions of 19 rare and 21 widespread congeneric plant species in Switzerland, while also accounting for variation in environmental conditions of the species' origin.

Results: Our results restrict the long-standing hypothesis that widespread species are superior competitors to rare species to only those species originating from resourcerich habitats, in which competition is usually strong. Tolerance to herbivory and ambient herbivore damage, on the other hand, did not differ between widespread and rare species. In accordance with the resource-availability hypothesis, widespread species from resource-rich habitats where more damaged by herbivores (less defended) than widespread species from resource-poor habitats-such a growth-defence trade-off was lacking in rare species. This indicates that the evolutionary important trade-off between traits increasing competitive ability and defence is present in widespread species but may have been lost or never evolved in rare species.

Main conclusions: Our results indicate that biotic interactions, above all competition, might indeed set range limits and underlines the importance of including context dependency in studies comparing traits of common and rare or invasive and noninvasive species.
\end{abstract}

\section{KEYWORDS}

competition, context dependency, experiment, herbivory, plant tolerance, range size, rarity, regional abundance, resource availability

Kempel and Vincent are joint first-authorship.

This is an open access article under the terms of the Creative Commons Attribution License, which permits use, distribution and reproduction in any medium, provided the original work is properly cited.

(c) 2020 The Authors. Diversity and Distributions published by John Wiley \& Sons Ltd. 


\section{1 | INTRODUCTION}

Understanding why some species are rare while others are widespread or invasive remains a fascinating question in ecology spanning decades (Baker, 1965; Gaston, 1994). There is a long-standing tradition of studies comparing rare and widespread species, or invasive and non-invasive species, in order to identify which factors cause plant species to be more or less successful than others. While early attempts were often restricted to a few species (Gaston, 1994; Murray, Thrall, Gill, \& Nicotra, 2002), the recent introduction of phylogenetically controlled multispecies experiments has provided powerful tests for general patterns of rarity or invasiveness (Dawson, Fischer, \& Kleunen, 2012; Van Kleunen, Weber, \& Fischer, 2010; van Kleunen, Dawson, Bossdorf, \& Fischer, 2014). However, attempts to identify traits or characteristics of rare and widespread or invasive species were often not successful or revealed contradictory results. One explanation for this is that certain plant traits or characteristics may benefit a species in some habitats, but in others may be costly (as they often trade-off, Kempel, Schädler, Chrobock, Fischer, \& Kleunen, 2011) or unimportant (Darwin, 1859; Louthan, Doak, \& Angert, 2015). This context dependency has frequently been invoked to explain that the drivers of plant success vary along environmental gradients (Funk \& Cornwell, 2013; van Kleunen, Dawson, \& Maurel, 2015; Kueffer, Pyšek, \& Richardson, 2013). However, context dependency has rarely been considered in experimental studies comparing characteristics of plants of widespread and rare, or invasive and non-invasive species.

In particular, biotic interactions can be highly context dependent, which can have strong effects on the fundamental niche of a species and may influence plant rarity or invasiveness (Pigot \& Tobias, 2013; van der Putten, Macel, \& Visser, 2010; Wisz et al., 2013). However, biotic interactions are rarely considered in studies explaining rarity and commonness (Brown, 1984; Hanski, Kouki, \& Halkka, 1993). For example, the strength of competition between plants strongly depends on resource availability, where resource-rich habitats exhibit strong above- and belowground competition (Tilman, 1988), in resource-poor habitat plants compete mainly for belowground resources, relaxing the strength of competitive exclusion (Grime, 1977; Hautier, Niklaus, \& Hector, 2009; Tilman, 1988) or even promoting facilitation among plants (Callaway et al., 2002). Concordantly, competition might be important for a plant's success in resource-rich environments, whereas in resource-limited environments success might rather be driven by abiotic factors (Connell, 1961; Louthan et al., 2015; Warren \& Bradford, 2011). Many widespread species occupy nutrient-rich environments and often have adaptations for high resource acquisition, whereas many regionally rare species are characterized by resource-conservatism and are thus limited to resource-poor environments (Drury, 1974; Grime, 1977). This has led to the long-standing hypothesis that widespread species are competitively superior over rare ones (Griggs, 1940; Powell \& Knight, 2009). However, if we compare the competitive ability of widespread and rare species, and by chance most rare species originate from resource-poor habitats and most widespread species from resource-rich habitats, results may be biased and simply reflect differences in the importance of competition along a resource axis (Dawson et al., 2012; Lloyd, Lee, \& Wilson, 2002). Therefore, if we want to adequately test for differences in the competitive ability of widespread and rare species, it is crucial to account for the position of a species along a resource gradient, and to compare rare and common species originating from both, resource-poor and rich habitats.

Another biotic interaction, which may strongly depend on environmental context, is the impact of plant enemies, such as herbivores, on their host plant and therefore the ability of a plant to defend against them or to tolerate them. Species which evolved in resource-poor environments are suggested to be less able to replace lost tissue and should thus invest more into defences than faster-growing, competitive species from more productive environments which can rapidly compensate biomass loss (growth-rate hypothesis, Coley, Bryant, \& Chapin, 1985). Accordingly, plants from productive environments should be more tolerant to herbivory or pathogen infestation than plants from resource-poor ones. Additionally, this could suggest that regionally rare plant species in general are less defended against enemies than widespread species, although this has rarely been tested (but see Kempel, Rindisbacher, Fischer, \& Allan, 2018; Landa \& Rabinowitz, 1983). Rare species often occur in small or isolated populations and may thus have a low genetic diversity, making them more susceptible to enemies (Spielman, Brook, Briscoe, \& Frankham, 2004). Alternatively, regionally rare plant species are often less apparent to their enemies than more widespread ones, reducing the likelihood for host specialization by herbivores or pathogens (Feeny, 1976). Such a reduced apparency to enemies could have led to the evolution of reduced defence, making rare plant species more susceptible to herbivory or pathogen attack if subsequently exposed (Laine, 2006). Consequently, if we compare rare and widespread plant species in their ability to resist or tolerate their enemies, and by chance most rare species originate from resource-poor and most widespread species from resource-rich habitats, our results may not reflect differences in rarity, but rather differences in resource deployment strategies along a resource gradient. Again, this highlights the importance of the inclusion of context dependency in studies comparing characteristics of rare and widespread plant species.

Here, we present a multispecies experiment where we compared the competitive ability, the tolerance to herbivory (i.e. the regrowth capacity to experimental clipping) and ambient herbivore damage (as an indication of plant resistance) between 19 regionally rare and endangered and 21 widespread plant species from Switzerland. To ensure that the differences presented are due to regional rarity (regional abundance) and are not confounded with local plant rarity (local abundance), we ensured that the same amount of rare and widespread species usually reach low and high abundances, respectively, at a local scale (Table 1). Rare and 
TABLE 1 Species selected for the experiment

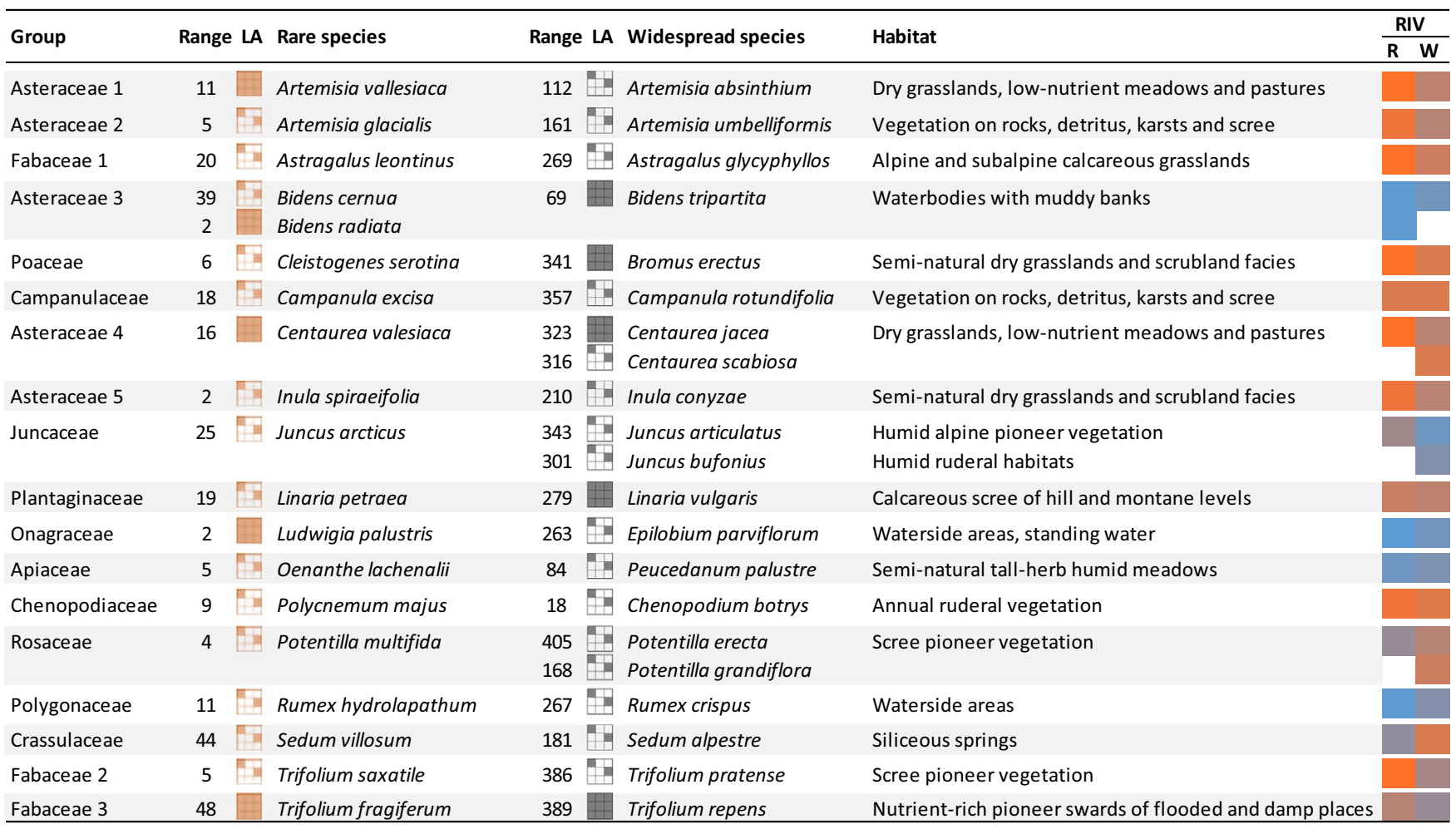

Note: Species were grouped according to phylogeny and habitat such that each group consists of at least one regionally rare and one widespread species from the same genus or family and occupying the same or a similar habitat. The regional abundance (Range) for each species is given as the number of $10 \times 10 \mathrm{~km}$ grid cells occupied by a given species in Switzerland. The local abundance (LA) of each species is depicted with symbols and indicates whether species usually grow in larger groups or stands at the place where they occur (locally abundant, $\square$ ), or whether they are usually scattered or only grow in small groups (locally scattered, $\$$ ). Resource indicator values (RIV) for rare (R) and widespread species (W) are depicted using a colour code with red and blue colours indicating dry and nutrient-poor, respectively, wet and nutrient-rich conditions.

widespread species were selected from a common genus or plant family to account for phylogenetic influences, and each species group originated from a similar habitat (Table 1). Habitats between species groups differed greatly in their resource availability. This allowed us to test for differences in the ability to cope with antagonistic biotic interactions of many widespread and rare species while accounting for variation in environmental and phylogenetic context. Additionally, we accounted for the possible interaction of competition with simulated herbivory and its potential dependence on resource availability, by applying a nutrient addition treatment and factorially assessing the interactions between plant rarity and the resource gradient.

\section{METHODS}

\section{1 | Plant species}

To test whether rare and widespread plant species respond differently to biotic interactions, we originally selected 52 plant species from a wide range of different habitats. These species differ in their degree of regional rarity and endangerment in Switzerland and in the resource availability of the habitat they typically occupy. We classified 27 plant species as "rare" and 25 plant species as "widespread" a priori. Rare species were listed as near-threatened, vulnerable, endangered or critically endangered according to the Red list for Switzerland (Moser, Gygax, Bäumler, Wyler, \& Palese, 2002) and had a relatively low regional abundance in Switzerland. Widespread species were listed as being of least concern except for three species, which were listed as near-threatened, but which had a relatively large regional abundance (and particularly larger than their rare congeneric partner, Table 1). We calculated the regional abundance of these species as the number of $10 \mathrm{x}$ $10 \mathrm{~km}$ grid cells occupied in Switzerland and found that rare species had a $94 \%$ smaller regional abundance than widespread species $\left(F_{1,38}=82 ; p<.0001\right.$, analysis done on the final selection of species). Next, to control for phylogenetic and habitat effects, we grouped rare and widespread species, so that groups contained at least one rare and one widespread species from the same genus or plant family and from the same habitat, resulting in 21 groups. Five species did not germinate in sufficient numbers and were excluded together with their congeneric partner from the analysis, ending up with 21 common and 19 rare species, forming 18 groups (Table 1). To ensure that the differences we report here are due to regional rarity and not local plant abundance, for both the rare and the widespread species, we selected some species that usually reach high abundances at a local scale and some species that usually occur in low abundances at the place where they occur 
("dominance in situ" from the Flora Indicativa, Landolt et al. (2010), values of our species range from 1-4, with 1 = scattered, 2 = scattered or in small groups, 3 = in larger groups, 4 = in larger stands, Table 1).

The habitats of our selected species differed mainly in their soil moisture and nutrient availability. Thus, to quantify the position of the realized niche optima of our species along a resource gradient, we used the ecological indicator values for nutrients and moisture after Landolt et al. (Flora Indicativa, 2010). Landolt indicator values describe the realized niche of species and habitat parameters, and follow an ordinal scale ranging from 1 to 5 (low numbers represent low, high numbers high nutrient and moisture requirements). They have been widely used in ecological studies (e.g., Diekmann, 2003). Nutrient and moisture values were correlated ( $r=.33, p=.017$ ). To avoid collinearity but maintain full environmental space, we calculated a principal component analysis and used the scores of the first axis for further analysis, hereafter named resource indicator value (explained variance $=72 \%$, values ranged from -1.89 to 2.19 with high values indicating that species originate from wet and nutrient-rich habitats, Figure S1, Table 1). Rare and widespread plant species did not differ in their resource indicator value $\left(F_{1,38}=0.504, p=.48\right)$. Seeds of rare plant species were collected in the wild (seeds of one population per species of at least 10 mother plants), and seeds of widespread plant species were either collected in the wild (seeds of one population per species of at least 10 mother plants) or obtained from commercial seed suppliers. Populations in which seeds were collected were located in the typical habitat for the species.

\section{2 | Experimental design}

In spring 2013, we sowed seeds of our species in trays. After germination, we transplanted 40 seedlings per species individually into $1.3-\mathrm{L}$ pots filled with mixed soil containing $20 \%$ compost, $20 \%$ agricultural field soil from Swiss Plateau region, $20 \%$ wood fibre and $40 \%$ peat. For seeds that were collected in the wild, we ideally used the same number of seedlings per mother plant. Pots were then placed outside in a common garden at Muri bei Bern $\left(46.9351^{\circ} \mathrm{N}, 7.4985^{\circ} \mathrm{E}\right.$, Switzerland). To test whether the species respond differently to biotic interactions at different levels of resources, we applied a fully factorial experiment, including a competition treatment $(\mathrm{C})$, a clipping treatment to simulate herbivory and to test for regrowth capacity $(\mathrm{H})$, and a fertilizer treatment to change resource supply experimentally (F). This allowed us to test how the response to competition and simulated herbivory changes with increasing resource supply and whether these responses differed between widespread and rare species. Clipping as a tool to simulate herbivory may not induce important plant responses and thus may lack realism. However, it may still be an appropriate method to investigate the regrowth capacity of plants. We applied all possible combinations of treatments resulting in 8 treatment combinations: Control, $\mathrm{C}, \mathrm{H}, \mathrm{F}, \mathrm{CH}, \mathrm{CF}, \mathrm{HF}$ and $\mathrm{CHF}(40$ species $\times 8$ treatment combinations $\times 5$ replicates $=1,600$ plants). However, five replicates per treatment and all treatment combinations were not always possible (1,351 plants in total, Table S1). Pots were then distributed among five blocks (one replicate per species and treatment combination per block) and pots receiving the same treatments were grouped together to facilitate the applications of the treatments.

For the competition treatment, we sowed $1 \mathrm{~g}$ of a common grass species, Lolium perenne, in pots of the competition treatment 5 weeks after transplanting seedlings. Although competition with one species may not reflect competition against all natural competitors, to make results comparable the same competitor for all species was chosen. L. perenne was selected as it is not likely to co-occur with any of the study species. For the clipping treatment, we simulated herbivory by removing ca. $50 \%$ of the leaf biomass of the target plants by clipping each leaf by half for herbs, or in the middle for grasses. For the fertilization treatment, we experimentally increased resource supply by fertilizing plants every 2 weeks with a soluble NPK fertilizer (Wuxal).

To get an indication of a plant's herbivore resistance, we visually recorded damage caused by ambient leaf chewing herbivores in the common garden on all plant species (percentage herbivore damage $=$ number of damaged leaves $x$ percentage damage of damaged leaves/total number of leaves) shortly before harvesting. The amount of herbivore damage has been suggested to be related to a plant investment in defence (e.g., Coley et al., 1985). In August 2013, we harvested aboveground biomass of all target plants and of the competitor Lolium perenne. Biomass was dried $\left(72 \mathrm{hr}\right.$ at $\left.70^{\circ} \mathrm{C}\right)$ and weighed. Unfortunately, belowground biomass was not assessed, because it was too laborious to separate and wash the roots of 1,351 plants.

\section{3 | Statistical analysis}

We used linear mixed-effect models (Imer, package Ime4 in R; R Core Team, 2013). To assess whether regionally rare plant species suffered more from competition or experimental clipping than widespread plant species, and whether this changes with fertilization, we used aboveground biomass (log-tranformed) of our target species as response variable and fitted status (widespread and rare), competition, clipping, fertilization and all possible combinations as fixed terms. To test whether the response to the treatments and differences between widespread and rare species depended on the resource availability of their habitat, we additionally fitted the species resource indicator value and all interactions with all other factors as fixed effects (see Table S3). Grasses or annuals may respond differently to competition or clipping than herbaceous or perennial plants. To account for this, we included functional group (grass and herb) and life-form (not perennial and perennial) in our model and all possible interactions, except higher-order interactions that involve status, resource indicator value, functional group or life-form which we had to remove, 
because we had too few grasses and annuals in our study to test for these interactions.

We also tested whether the effect of our plants on the biomass of the competitor L. perenne depended on rarity, resource origin, clipping or fertilizer, and used aboveground biomass (log-transformed) of $L$. perenne as response variable and all factors and interactions as above (except those involving competition) as fixed terms.

Further, we tested whether the amount of ambient herbivory was related to rarity, resource indicator value and all treatments, and used the percentage leaf damage (arcsine square root transformed) as a response variable and included the same factors as in the model for aboveground biomass as fixed terms.

In the model for the biomass of the competitor L. perenne, we either included or excluded the final biomass of the target species as a covariable. In all models, we included species (40 levels) nested into groups (18 levels, congeneric or confamilar, Table 1) and plant family (12 levels), and block (five levels) as random terms. We simplified the best model (but kept the main factors status, resource indicator value, clipping, competition and fertilization in the models) and derived significances using likelihood-ratio tests comparing models with and without the factor of interest (Zuur, 2009).

\section{3 | RESULTS}

\section{1 | Biomass of rare and common species}

Overall, widespread plant species had a $34 \%$ greater biomass than rare plant species (Figure 1, Status: $\chi^{2}=4.07, p=.044$, Table S2). Competition with $L$. perenne and simulated herbivory by experimental clipping reduced plant biomass by $7 \%$ and $21 \%$, respectively (Competition: $\chi^{2}=10.4, p=.001$; clipping: $\chi^{2}=82.22, p<.0001$ ), whereas fertilization alone had no effect on plant biomass (Table S2). In general, common and rare plant species did not differ in their response to competition (no significant Competition $\times$ Status interaction), their response to experimental clipping (no significant Clipping $\times$ Status interaction) nor in their response to fertilization (no significant Fertilizer $\times$ Status interaction, Table S2).

Grasses and herbs and annual and perennial species did not differ in their aboveground biomass (Functional Group and Life-form not significant, Table S2). However, annual plants were less affected by competition than perennial plants (Competition $\times$ Life-form interaction: $\chi^{2}=5.25, p=.022$, Table S2).

The effect of competition depended on the resource indicator value (Competition $\times$ Resource origin interaction: $\chi^{2}=14.56$, $p=.0001$, Table S2), whereas the effect of clipping and fertilization did not depend on the resource indicator value. Competition had especially strong negative effects on species with a high resource indicator value. When species had a high resource indicator value, that is originated from nutrient-rich and moist habitats, rare plant species suffered more from competition than common plant species (Figure 1, Status $\times$ Competition $\times$ Resource indicator interaction: $\chi^{2}=9.03, p=.003$, Table S2). In contrast, for plants with a low resource indicator value, that is plants originating from nutrient-poor and dry habitats, common and rare species did not differ in their response to competition.

When plants had been fertilized, the combined effects of competition and clipping had the strongest negative effects on plant biomass, whereas in non-fertilized pots clipping and competition combined had as negative effects on plant biomass as clipping alone (Fertilizer $\times$ Competition $\times$ Clipping interaction: $\chi^{2}=4.62$, $p=.032$, Table S2 and Figure S2), indicating that biomass loss due to herbivory or mowing can be more easily tolerated under high nutrient conditions, where resources for a fast regrowth are more abundant.

Further, fertilization alleviated the negative effects of clipping, but only for plants with a high resource indicator value (Fertilizati on $\times$ Clipping $\times$ Resource indicator interaction: $\chi^{2}=5.17, p=.023$ ) Clipping similarly reduced biomass of unfertilized and fertilized plants with a low resource indicator value, whereas for plants with a high resource indicator value, and the negative effect of clipping was smaller when plants had been fertilized (Figure S3). This indicates that plants from resource-rich origins are the ones that can better tolerate biomass loss under high nutrient conditions, potentially due to their better ability to monopolize belowground resources for regrowth. However, this pattern might also arise because the unclipped plants could not profit from fertilization, potentially because they were already pot-bound. We would thus interpret the finding that species from resource-rich habitats are better able to tolerate herbivory under high nutrient conditions with caution.

\subsection{Biomass of the competitor Lolium perenne}

The biomass of the competitor Lolium perenne was $19 \%$ higher when it was growing with rare plant species compared to common plant species, indicating that common species had a stronger competitive effect on L. perenne (Status: $\chi^{2}=4.95, p=.026$, Table S3, Figure 2). When we included biomass of the target species as a covariable, common and rare species only marginally differed in their effect on $L$. perenne, indicating that the stronger negative effect of common species is mainly driven by their higher aboveground biomass (Status: $\chi^{2}=3.16, p=.075$, Table S3). In both models, the biomass of L. perenne was lower when neighbouring plants had a low resource indicator value (i.e., originated from nutrient-poor and dry habitats) than when they had a high resource indicator value (Resource origin: $\chi^{2}=4.11, p=.042$ ) and this effect became stronger when we accounted for differences in aboveground biomass of the target species (Resource indicator value, with biomass of the target plants as covariable: $\chi^{2}=7.23, p=.007$, Table S3, Figure 2 ). This might indicate that for $L$. perenne, belowground competition with species from resource-poor habitats is stronger than with species from the resource-rich end. 
FIGURE 1 Aboveground biomass (log-transformed, in g) of rare (red) and regionally common (white) plant species without and with competition originating from low, medium or high resource habitats (resource indicator values -1.7 , 0.15 and 2, respectively). Shown are fitted estimates from a linear mixed-effect model. Error bars indicate confidence intervals (obtained from the effect package in $\mathrm{R}$ )

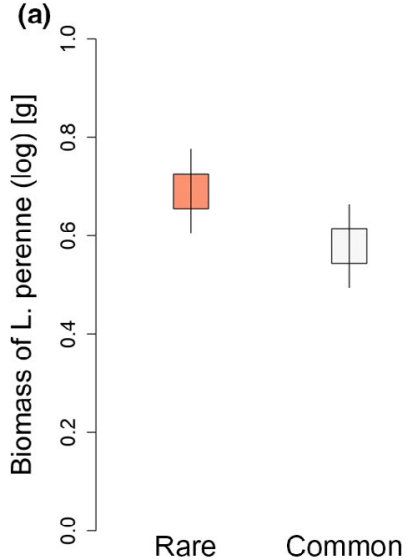

Low resources

Medium resources

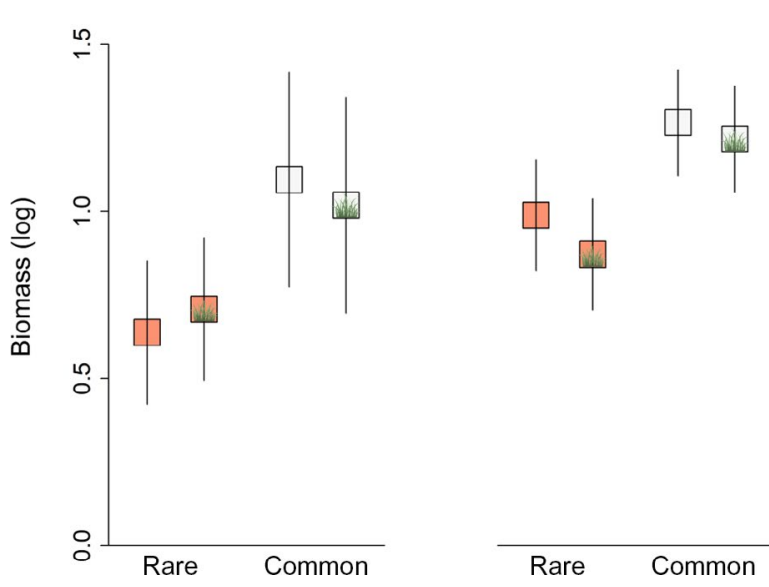

High resources

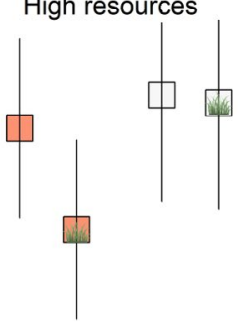

with competitior

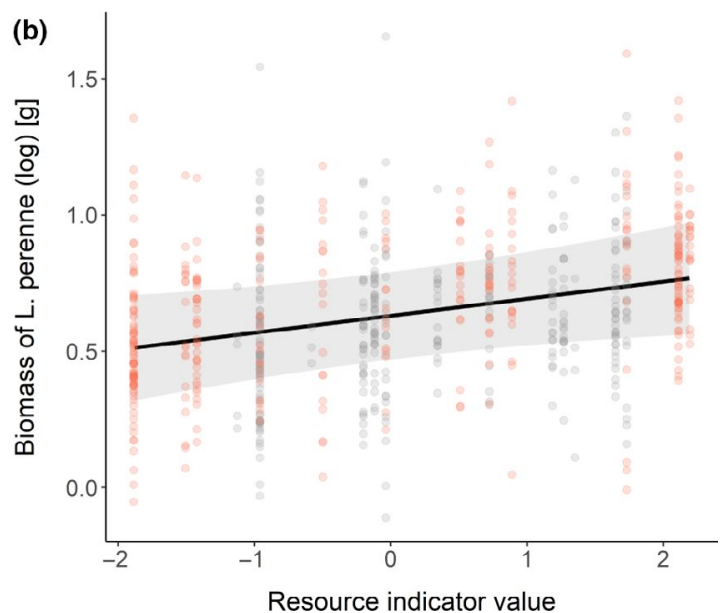

FIGURE 2 Biomass of the competitor L. perenne growing with (a) rare and regionally common plant species, when the biomass of the target species was not included as a covariable, and with (b) both rare and common plant species originating from habitats of different nutrient and moisture values, when their biomass was included as a covariate in the model. High values of resource indicator values indicate that a species originate from nutrient-rich and moist habitats, low values indicate that a species originate from nutrient-poor and dry habitats. Shown are the fitted values, respectively, lines, and partial residuals from a linear mixed-effect model. The error bars, respectively, shaded area, indicate lower and upper confidence intervals (obtained from the effect package in R). The points are partial residuals obtained from the visreg package (red = rare species, grey = regionally common species). When we accounted for the biomass of the target species, biomass of $L$. perenne did not significantly differ between regionally common and rare species

\section{3 | Herbivore damage}

Overall, the percentage of herbivore damage was not affected by competition or fertilization and was reduced when plants were clipped (Table S4). Herbivore damage did not differ between common and rare plant species (Status: $\chi^{2}=0.20, p=.65$, Table S4), and was not related to the resource indicator value of a species (Resource origin: $\chi^{2}=0.051$, $p=.82$ ). However, the percentage of herbivore damage increased with a species' resource indicator value in common species, whereas in rare species the percentage of herbivore damage did not change with a species' resource indicator value $\left(\chi^{2}=4.93, p=.026\right.$, Figure 3$)$. This indicates a trade-off between fast growth and competitive ability on one hand and defence on the other hand in widespread species but no such trade-off in rare species, which showed intermediate levels of herbivore damage, independent of their position along a resource gradient.

\section{4 | DISCUSSION}

Although biotic interactions are increasingly recognized as important factors in determining species range limits (Pigot \& Tobias, 2013; van der Putten et al., 2010; Wisz et al., 2013), evidence that rare and widespread species respond differently particularly to antagonistic biotic interactions is still scarce and often contradictory, potentially because the importance of certain plant characteristics for a plants' success is context dependent (e.g., Dawson et al., 2012; Powell \& Knight, 2009; Rabinowitz, Rapp, \& Dixon, 1984). In our multispecies experiment, using 40 plant species differing in regional rarity and originating from contrasting habitats, we show that taking into account phylogenetic and environmental context dependency is important when comparing widespread and rare or invasive and non-invasive species. 


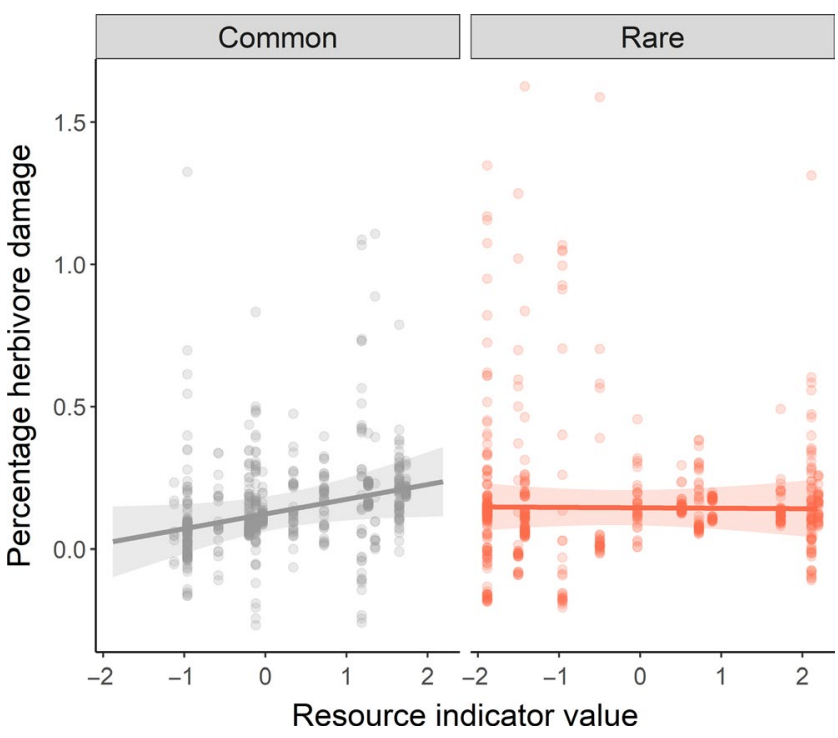

FIGURE 3 Percentage herbivore damage (arc-sinus square root transformed) on rare and regionally common plant species with different resource indicator values. High resource indicator values indicate that a species originate from nutrient-rich and moist habitats and low values indicate that a species originate from nutrient-poor and dry habitats. Shown are the fitted lines from a liner mixed-effect model and the lower and upper confidence intervals (obtained from the effect package). Points are partial residuals obtained from the visreg package

\section{1 | Competitive ability, rarity and resource origin}

Although the importance of interspecific competition along a resource gradient has long been debated (Grace, 1991; Grime, 1979; Tilman, 1988), it seems obvious that plant characteristics leading to success in resource-rich habitats differ from those leading to success in resource-limited habitats. This is because resources for which species are competing differ, mainly light in nutrient-rich and moist habitats and nutrients and water in nutrient limited and dry habitats (Connell, 1961; Grime, 1979; Wilson \& Tilman, 1991). Accordingly, characteristics of species from resource-rich habitats comprise traits leading to fast growth and rapid capture of light and belowground resources whereas species from resource-limited habitats possess traits leading to nutrient retention. Both adaptive strategies are suggested to trade-off (Aerts, 1999; Reich, 2014).

Therefore, it is not surprising that studies comparing the competitive ability of rare and common species or invasive and non-invasive alien species often find contradictory results when the ecological context is not considered (e.g., Dawson et al., 2012; Powell \& Knight, 2009; Rabinowitz et al., 1984). For example, Dawson et al. (2012) experimentally compared the competitive response of rare and common species from both native and alien habitats and found a tendency for higher survival in the presence of competition in more common (native or alien) species. However, this effect disappeared when they corrected for the fact that most rare species originated from resource-poor and most common species from resource-rich habitats.

In our experiment, using 40 plant species differing in regional rarity and originating from a wide range of habitats, we show that widespread species suffered less from competition than rare species, but only when both widespread and rare species originated from nutrient-rich and moist habitats. Instead, when species originated from more nutrient limited and drier habitats, widespread and rare species were similarly affected by competition. At least for species originating from habitats where aboveground competition for light is usually strong, our results support the long-standing hypothesis that common species are competitively superior compared to rare species (Griggs, 1940). It is thus likely that a higher competitive ability in these habitats has helped them to expand their ranges and to become common; hence, competition could potentially set range limits in abiotically less stressful conditions.

For species from resource-poor and dry habitats, a high ability to tolerate low levels of nutrients and water rather than a high competitive ability for light is important (Tilman, 1988). In our experiment, fertilization surprisingly did not have a consistent positive effect, indicating that nutrients were not limited. Thus, we cannot test whether widespread species from resource-limited habitats would have performed better under dry and nutrient limited conditions than rarer species. Whether certain species from resource-poor environments are widespread because they can better tolerate low levels of nutrients and dry conditions, or whether they are stronger competitors for belowground resources, remains to be resolved. For species from resource-rich habitats, however, it seems that indeed the outcome of biotic interactions such as competition could be an important driver of large-scale plant rarity and is likely to determine range limits of species.

The competitive ability of a species comprises not only of its response to competition but also of the ability of a plant to suppress the growth of other plants, that is the competitive effect (Goldberg, 1990). Widespread species in our experiment generally had stronger negative effects on the competitor $L$. perenne than rare species. This was mainly because widespread species had a higher aboveground biomass, which is consistent with previous studies (Cornwell \& Ackerly, 2010; Dawson et al., 2012; Lavergne, Garnier, \& Debussche, 2003; Murray et al., 2002). Interestingly, whether a plant had a strong or weak effect on the growth of L. perenne also depended on whether it originated from a resource-poor or rich habitat: plants from nutrient-poor and dry habitats had stronger negative effects on L. perenne than plants originating from nutrient-rich and moist habitats. Likely, this is caused by traits related to stronger belowground competition such as a larger rooting system associated with plants originating from resource-poor compared resource-rich environments (Tilman, 1988). However, this pattern could also be caused by different allelopathic activities or by different microbial communities 
surrounding roots of species from contrasting environments (Inderjit, Wardle, Karban, \& Callaway, 2011; Kempel et al., 2018). In summary, widespread species from resource-rich environments not only suffer less from competition than rare species, but in general widespread species have stronger negative effects on other plants due to their larger biomass, which may both contribute to their large range sizes.

\subsection{Tolerance and resistance to herbivory, plant rarity and resource origin}

Herbivores have been shown to have strong effects on the relative abundance and composition of species in communities (e.g., Allan \& Crawley, 2011; McNaughton, 1979), however, whether and they can determine patterns of large-scale plant rarity, and their potential mechanisms in doing so, have yet to be proven. Plants can cope with herbivores by increasing their tolerance or their resistance (Karban \& Baldwin, 1997), and although variation in these attributes differs greatly between species, they have rarely been related to large-scale rarity.

We did not find that widespread and rare species respond differently to experimentally simulated herbivory, and therefore found that tolerance is unrelated to large-scale patterns of plant rarity. Additionally, whether a species originated from resource-poor or rich habitats did not generally affect its regrowth capacity, although there was an interaction of fertilization, clipping and resource indicator value. This showed that fertilization could alleviate the negative effects of clipping, but only for those plants that originated from nutrient-rich and moist habitats (Figure S3). However, this pattern might have arisen because our fertilizer treatment did not show the expected positive effect on unclipped plants, likely because these plants were already pot-bound due to their high biomass.

How abiotic or biotic factors affect tolerance to herbivory is still largely unclear (Fornoni, 2011; Strauss \& Agrawal, 1999; Wise \& Abrahamson, 2007). In accordance to the resource-availability hypothesis (Coley et al., 1985) fast growing species with rapid rates of nutrient absorption from nutrient-rich environments have been found to have high levels of tolerance (Gianoli \& Salgado-Luarte, 2017). Others found that nutrient availability is negatively related to tolerance (see Strauss \& Agrawal, 1999; Wise \& Abrahamson, 2007), because high nutrient levels reduce the amount of roots relative to shoots, which in turn reduces regrowth capacity. Species with effective nutrient retention and a large root system, which are often found in resource-poor environments, should thus be more tolerant. As we found no relationship between plant tolerance and the position of our species along a resource axis, it is likely that under our experimental nutrient-rich conditions, both strategies-rapid rates of nutrient uptake and a large root system-led to high levels of plant tolerance. However, we can only speculate about the potential larger root system in plants from resource-poor environments, as we did not measure belowground biomass in our experiment. In conclusion, our study indicates that plant tolerance alone does not seem to be related to large-scale plant rarity and commonness when species habitat characteristics are taken into account, likely because tolerance together with resistance are both strategies for plants to cope with herbivory.

Only few studies have tested whether widespread or rare plants differ in their resistance to herbivores or other plant enemies. Landa and Rabinowitz (1983) found that a common grasshopper preferred rare species over more apparent and widespread grass species (seven species), Fiedler (1987) found that rare species are more prone to leaf grazing (four species), supporting the idea that apparent plants are more defended. Similarly, Kempel et al. (2018) showed that rare plant species were more susceptible to soil biota than widespread species (19 species), indicating that defences are lower in rarer species.

In our study, we found no evidence that rare species are more susceptible to ambient leaf herbivory, and thus that they are less defended than widespread species. Interestingly however, the level of herbivore damage on widespread plants depended strongly on whether plants originated from resource-rich or low habitats. This is consistent with the resource-availability hypothesis, where plants from resource-rich habitats were more damaged (indicating that they are less defended) than species from resource-poor habitats. In contrast, rare species showed intermediate levels of damage over all resource origins. It therefore seems as if the trade-off between traits that increase competitive ability and defence is only present for widespread species-likely a successful adaptation to changes in the relative importance of herbivory and competition for plant success along a resource axis. In resource-rich habitats, a low investment in defences might allow plants to be competitively superior, particularly if plants are less limited by herbivores than by competing neighbouring plants. Rare species, which often have undergone bottlenecks and show low levels of genetic diversity (Gaston, 1994), might have lost such adaptations and this might have disconnected trade-offs (Kempel et al., 2011). Alternatively, it might be that such trade-offs never evolved in species, which have always been regionally rare. Although this is only speculative, the potentially higher investment in defence for rare species from resource-rich habitats might be one explanation as to why they are less competitive compared to widespread species. So far, our data does not indicate that rare and widespread species generally differ in their tolerance and their susceptibility to herbivores. Moreover, the explained variation in the model of herbivore damage was very low (Table S4). We therefore suggest that future studies should test these ideas more rigorously, also incorporating tests of the preference or performance of herbivores, and measurements on the chemical investment of plants. Nevertheless, it might be insightful to further investigate whether important evolutionary trade-offs are absent in rare species. 


\section{3 | Multispecies experiments}

Ecological studies inevitably face a trade-off between being realistic and obtaining generality (van Kleunen et al., 2014). If multispecies experiments are designed in a way that they simulate the natural environment for each individual species, then this would be very realistic, but species are no longer comparable with each other. Most multispecies experiments therefore grow species under common environmental conditions, using the same soil or the same competitor species. This might not mirror realistic conditions for all experimental species but does allow a direct comparison between them. This is important to address ecological questions at a broader scale (van Kleunen et al., 2014).

\section{5 | CONCLUSION}

Our multispecies experiment controlling for phylogenetic and environmental context supports the long-standing hypothesis that regionally common species are better competitors than rare species, but restricts it to only those species originating from resource-rich habitats, in which a high competitive ability is advantageous. Using many species from a large number of environmental conditions suggests that this is a general pattern. It is thus likely that competitive interactions might be important drivers of large-scale plant rarity. Our results clearly illustrate the importance of context dependency, and how many inconsistencies between studies comparing characteristics of common and rare or invasive and non-invasive species could potentially be explained if we would consider that the importance of certain species characteristics for plant success might differ depending on environmental conditions.

Altogether, our data hint at the fact that species' responses to biotic interactions, above all to plant competition, are also important drivers of species range limits. Increasing our understanding not only in environmental, biogeographical or historical but also biotic drivers underlying species range distributions is therefore of utmost importance if we are to understand and predict species responses to global change, and to conserve today's biodiversity.

\section{ACKNOWLEDGEMENTS}

We thank Karl Kaspar and Judith Hinderling for help with the common garden experiment and the Federal Office for the Environment (FOEN) for funding. We would further like to thank Tosca Mannall for proofreading and the editor and two anonymous referees for their very constructive comments on an earlier version of this paper.

\section{DATA AVAILABILITY STATEMENT}

The data that support the findings of the study are openly available at Dryad. https://doi.org/10.5061/dryad.xksn02vbz.

\section{ORCID}

Anne Kempel (iD https://orcid.org/0000-0002-0563-901X

\section{REFERENCES}

Aerts, R. (1999). Interspecific competition in natural plant communities: Mechanisms, trade-offs and plant-soil feedbacks. Journal of Experimental Botany, 50(330), 29-37. https://doi.org/10.1093/ $\mathrm{jxb} / 50.330 .29$

Allan, E., \& Crawley, M. J. (2011). Contrasting effects of insect and molluscan herbivores on plant diversity in a long-term field experiment. Ecology Letters, 14(12), 1246-1253. https://doi. org/10.1111/j.1461-0248.2011.01694.x

Baker, H. G. (1965). Characteristics and modes of origin of weeds. In H. G. Baker, \& G. L. Stebbins (Eds.), The genetics of colonizing species. Cambridge, MA: Academic Press.

Brown, J. H. (1984). On the relationship between abundance and distribution of species. The American Naturalist, 124(2), 255-279. https:// doi.org/10.1086/284267

Callaway, R. M., Brooker, R. W., Choler, P., Kikvidze, Z., Lortie, C. J., Michalet, R., ... Cook, B. J. (2002). Positive interactions among alpine plants increase with stress. Nature, 417, 844. https://doi. org/10.1038/nature00812

Coley, P. D., Bryant, J. P., \& Chapin, F. 3rd (1985). Resource availability and plant antiherbivore defense. Science, 22, 895-899. https://doi. org/10.1126/science.230.4728.895

Connell, J. H. (1961). The influence of interspecific competition and other factors on the distribution of the barnacle Chthamalus Stellatus. Ecology, 42(4), 710-723. https://doi.org/10.2307/1933500

Cornwell, W. K., \& Ackerly, D. D. (2010). A link between plant traits and abundance: Evidence from coastal California woody plants. Journal of Ecology, 98(4), 814-821. https://doi.org/10.1111/j.1365-2745. 2010.01662.x

Darwin, C. (1859). On the origin of the species by means of natural selection. London, UK: John Murray.

Dawson, W., Fischer, M., \& van Kleunen, M. (2012). Common and rare plant species respond differently to fertilisation and competition, whether they are alien or native. Ecology Letters, 15(8), 873-880. https://doi.org/10.1111/j.1461-0248.2012.01811.x

Diekmann, M. (2003). Species indicator values as an important tool in applied plant ecology - A review. Basic and Applied Ecology, 4(6), 493506. https://doi.org/10.1078/1439-1791-00185

Drury, W. H. (1974). Rare species. Biological Conservation, 6(3), 162-169. https://doi.org/10.1016/0006-3207(74)90061-5

Feeny, P. (1976). Plant apparency and chemical defense. In J. M. Wallace, \& R. L. Mansell (Eds.), Biochemical interaction between plants and insects (vol. 10). Berlin, Germany: Springer.

Fiedler, P. L. (1987). Life history and population dynamics of rare and common Mariposa Lilies (Calochortus Pursh: Liliaceae). Journal of Ecology, 75(4), 977-995. https://doi.org/10.2307/2260308

Fornoni, J. (2011). Ecological and evolutionary implications of plant tolerance to herbivory. Functional Ecology, 25(2), 399-407. https://doi. org/10.1111/j.1365-2435.2010.01805.x

Funk, J. L., \& Cornwell, W. K. (2013). Leaf traits within communities: Context may affect the mapping of traits to function. Ecology, 94(9), 1893-1897. https://doi.org/10.1890/12-1602.1

Gaston, K. J. (1994). Rarity. Dordrecht, The Netherlands: Springer.

Gianoli, E., \& Salgado-Luarte, C. (2017). Tolerance to herbivory and the resource availability hypothesis. Biology Letters, 13(5), 20170120. https://doi.org/10.1098/rsbl.2017.0120

Goldberg, D. E. (1990). Components of resource competition in plant communities. In J. B. Grace, \& D. Tilman (Eds.), Perspectives on plant competition (pp. 27-49). Cambridge, MA: Academic Press, Inc.; CABDirect.

Grace, J. B. (1991). A clarification of the debate between Grime and Tilman. Functional Ecology, 5(5), 583-587. https://doi.org/10.2307/2389475

Griggs, R. F. (1940). The ecology of rare plants. Bulletin of the Torrey Botanical Club, 67, 575-594. https://doi.org/10.2307/2481578 
Grime, J. P. (1977). Evidence for the existence of three primary strategies in plants and its relevance to ecological and evolutionary theory. The American Naturalist, 111(982), 1169-1194. https://doi. org $/ 10.1086 / 283244$

Grime, J. P. (1979). Plant strategies and vegetation process. Hoboken, NJ: John Wiley.

Hanski, I., Kouki, J., \& Halkka, A. (1993). Three explanations of the positive relationship between distribution and abundance of species. In R. E. Ricklefs, \& D. Schluter (Eds.), Species diversity in ecological communities: Historical and geographical perspectives (pp. 108-116). Chicago, IL: University of Chicago Press.

Hautier, Y., Niklaus, P. A., \& Hector, A. (2009). Competition for light causes plant biodiversity loss after eutrophication. Science, 324(5927), 636. https://doi.org/10.1126/science.1169640

Inderjit, D., Wardle, D. A., Karban, R., \& Callaway, R. M. (2011). The ecosystem and evolutionary contexts of allelopathy. Trends in Ecology \& Evolution, 26(12), 655-662. https://doi.org/10.1016/j. tree.2011.08.003

Karban, R., \& Baldwin, I. T. (1997). Induced responses to herbivory. Chicago, IL: University Chicago Press.

Kempel, A., Rindisbacher, A., Fischer, M., \& Allan, E. (2018). Plant soil feedback strength in relation to large-scale plant rarity and phylogenetic relatedness. Ecology, 99(3), 597-606. https://doi.org/10.1002/ ecy. 2145

Kempel, A., Schädler, M., Chrobock, T., Fischer, M., \& van Kleunen, M. (2011). Tradeoffs associated with constitutive and induced plant resistance against herbivory. Proceedings of the National Academy of Sciences of the United States of America, 108(14), 5685. https://doi. org/10.1073/pnas.1016508108

Kueffer, C., Pyšek, P., \& Richardson, D. M. (2013). Integrative invasion science: Model systems, multi-site studies, focused meta-analysis and invasion syndromes. New Phytologist, 200(3), 615-633. https:// doi.org/10.1111/nph.12415

Laine, A.-L. (2006). Evolution of host resistance: Looking for coevolutionary hotspots at small spatial scales. Proceedings of the Royal Society B: Biological Sciences, 273(1584), 267-273. https://doi.org/10.1098/ rspb. 2005.3303

Landa, K., \& Rabinowitz, D. (1983). Relative preference of Arphia Sulphurea (Orthoptera: Acrididae) for sparse and common prairie grasses. Ecology, 64(2), 392-395. https://doi.org/10.2307/1937084

Landolt, E., Bäumler, B., Erhardt, A., Hegg, O., Klötzli, F., Lämmler, W., ... Wohlgemuth, T. (2010). Ecological indicator values and biological attributes of the flora of Switzerland and the alps. Bern, Switzerland: Haupt Verlag.

Lavergne, S., Garnier, E., \& Debussche, M. (2003). Do rock endemic and widespread plant species differ under the Leaf-Height-Seed plant ecology strategy scheme? Ecology Letters, 6(5), 398-404. https://doi. org/10.1046/j.1461-0248.2003.00456.x

Lloyd, K. M., Lee, W. G., \& Wilson, J. B. (2002). Competitive abilities of rare and common plants: Comparisons using Acaena (Rosaceae) and Chionochloa (Poaceae) from New Zealand. Conservation Biology, 16(4), 975-985. https://doi. org/10.1046/j.1523-1739.2002.01033.x

Louthan, A. M., Doak, D. F., \& Angert, A. L. (2015). Where and when do species interactions set range limits? Trends in Ecology \& Evolution, 30(12), 780-792. https://doi.org/10.1016/j.tree.2015.09.011

McNaughton, S. J. (1979). Grazing as an optimization process: Grassungulate relationships in the Serengeti. The American Naturalist, 113(5), 691-703. https://doi.org/10.1086/283426

Moser, D. M., Gygax, A., Bäumler, B., Wyler, N., \& Palese, R. (2002). Rote Liste der gefährdeten Arten der Schweizer Farn- und Blütenpflanzen. Bern, Switzerland: BUWAL.
Murray, B. R., Thrall, P. H., Gill, A. M., \& Nicotra, A. B. (2002). How plant life-history and ecological traits relate to species rarity and commonness at varying spatial scales. Austral Ecology, 27(3), 291-310. https:// doi.org/10.1046/j.1442-9993.2002.01181.x

Pigot, A. L., \& Tobias, J. A. (2013). Species interactions constrain geographic range expansion over evolutionary time. Ecology Letters, 16(3), 330-338. https://doi.org/10.1111/ele.12043

Powell, K. I., \& Knight, T. M. (2009). Effects of nutrient addition and competition on biomass of five cirsium species (Asteraceae), including a serpentine endemic. International Journal of Plant Sciences, 170(7), 918-925. https://doi.org/10.1086/600140

R Core Team (2013). R: A language and environment for statistical computing. Vienna, Austria: R Foundation for Statistical Computing.

Rabinowitz, D., Rapp, J. K., \& Dixon, P. M. (1984). Competitive abilities of sparse grass species: Means of persistence or cause of abundance. Ecology, 65(4), 1144-1154. https://doi.org/10.2307/1938322

Reich, P. B. (2014). The world-wide 'fast-slow' plant economics spectrum: A traits manifesto. Journal of Ecology, 102(2), 275-301. https:// doi.org/10.1111/1365-2745.12211

Spielman, D., Brook, B. W., Briscoe, D. A., \& Frankham, R. (2004). Does inbreeding and loss of genetic diversity decrease disease resistance? Conservation Genetics, 5(4), 439-448. https://doi.org/10.1023/ B:COGE.0000041030.76598.cd

Strauss, S. Y., \& Agrawal, A. A. (1999). The ecology and evolution of plant tolerance to herbivory. Trends in Ecology \& Evolution, 14(5), 179-185. https://doi.org/10.1016/S0169-5347(98)01576-6

Tilman, D. (1988). Plant strategies and the dynamics and structure of plant communities. Princeton, NJ: Princeton University Press.

van der Putten, W. H., Macel, M., \& Visser, E. (2010). Predicting species distribution and abundance responses to climate change: Why it is essential to include biotic interactions across trophic levels. Philosophical Transactions of the Royal Society B: Biological Sciences, 365(1549), 2025-2034. https://doi.org/10.1098/rstb.2010.0037

van Kleunen, M., Dawson, W., Bossdorf, O., \& Fischer, M. (2014). The more the merrier: Multi-species experiments in ecology. Basic and Applied Ecology, 15(1), 1-9. https://doi.org/10.1016/j.baae.2013.10.006

van Kleunen, M., Dawson, W., \& Maurel, N. (2015). Characteristics of successful alien plants. Molecular Ecology, 24(9), 1954-1968. https:// doi.org/10.1111/mec.13013

Van Kleunen, M., Weber, E., \& Fischer, M. (2010). A meta-analysis of trait differences between invasive and non-invasive plant species. Ecology Letters, 13(2), 235-245. https://doi. org/10.1111/j.1461-0248.2009.01418.x

Warren, R. J., \& Bradford, M. A. (2011). The shape of things to come: Woodland herb niche contraction begins during recruitment in mesic forest microhabitat. Proceedings of the Royal Society B: Biological Sciences, 278(1710), 1390-1398. https://doi.org/10.1098/ rspb.2010.1886

Wilson, S. D., \& Tilman, D. (1991). Component of plant competition along an experimental gradient of nitrogen availability. Ecology, 72(3), 1050-1065. https://doi.org/10.2307/1940605

Wise, M. J., \& Abrahamson, W. G. (2007). Effects of resource availability on tolerance of herbivory: A review and assessment of three opposing models. The American Naturalist, 169(4), 443-454. https://doi. org/10.1086/512044

Wisz, M. S., Pottier, J., Kissling, W. D., Pellissier, L., Lenoir, J., Damgaard, C. F., ... Svenning, J.-C. (2013). The role of biotic interactions in shaping distributions and realised assemblages of species: Implications for species distribution modelling. Biological Reviews, 88(1), 15-30. https://doi.org/10.1111/j.1469-185X.2012.00235.x

Zuur, A. F. (2009). Mixed effect models and extensions in ecology with $R$ (1st ed.). Berlin, Germany: Springer. 


\section{BIOSKETCH}

Anne Kempel is a community ecologist interested in the factors that maintain biodiversity and ecosystem functioning. Particularly, her work focusses on how biotic interactions, such as between plants and their enemies or mutualists, contribute to biodiversity maintenance, the distribution of plant species and the functioning of ecosystems, and how such interactions vary along abiotic or biotic gradients. Hugo Vincent is a plant ecologist interested in the causes and consequences of plant rarity and evolution and is currently the project manager of a large Biodiversity experiment (PaNDiv) in Switzerland. Daniel Prati is a plant population ecologist, interested ecological genetics, life-history evolution and species interactions. Markus Fischer is Professor of Plant Ecology. Most of his research is concerned with causes and consequences of biodiversity change, with the ecology and evolution of rare and invasive plants, with conservation biology and with the role of nature for sustainable development.

Author contributions: A.K., H.V. and M.F. designed the experiment; A.K. and H.V. performed research; A.K. analysed the data and wrote the first draft of the manuscript with substantial input from D.P.; and all authors contributed substantially to revisions.

\section{SUPPORTING INFORMATION}

Additional supporting information may be found online in the Supporting Information section.

How to cite this article: Kempel A, Vincent $\mathrm{H}$, Prati D, Fischer $M$. Context dependency of biotic interactions and its relation to plant rarity. Divers Distrib. 2020;26:758-768. https://doi. org/10.1111/ddi.13050 